\title{
PRESENT AND PERSPECTIVES OF THE INTELLECTUAL CAPITAL MANAGEMENT IN ROMANIAN UNIVERSITY ENVIRONMENT
}

Radu Bucea Manea Tonis Hyperion University, Romania E-mail:radub_m@yahoo.com

Cezar Braicu Hyperion University, Romania E-mail: cezar_braicu@hotmail.com

Submission: $12 / 06 / 2018$

Revision: 12/19/2018 Accept: 1/05/2019

\section{ABSTRACT}

The theory of organizational learning seems to be practical when researchers can find connections between two or more variables that can be justified and implemented. The term "intellectual capital" has appreciated over time acquiring a growing value. Work based on sustained learning contributes to the development of the intellectual capital not only of the employers, but also of the universities. In the current period of "knowledge economy" and "corporate university" development, the creation and evaluation of knowledge are recognized as important and necessary to be included in the educational programs. Knowledge management regards tacit and explicit knowledge. During the theoretical training, students mainly access information in written or verbal format, transmitted mainly on the teacher-student communication channel. During practical activities and mutual interactions, students agree to the informal knowledge, highly sought after by employers. In this paper, we will deal mainly with the ways of coding the information of statistical interest, which will be subject to a meta-level coding at the programming languages level, applicable to the analysis of the central trend and the shape of the data series distribution by estimating the parameters of the regression equation. 
INDEPENDENT JOURNAL OF MANAGEMENT \& PRODUCTION (IJM\&P)

http://www.ijmp.jor.br

V. 10, n. 5, September-October 2019

ISSN: 2236-269X

DOI: 10.14807/ijmp.v10i5.924

According to the analysis, it results that in the absence of some measures to stimulate birth rate or attract foreign students, the Romanian higher education will register a considerable decline compared to the reference period in terms of the number of enrolled students.

Keywords: knowledge management, intellectual capital, university environment, information

\section{INTRODUCTION}

The education system of a nation occupies one of the most important places for the development of that nation, given that it envisages the transfer of knowledge, the development of human creativity, allowing the personal and social ascension of individuals.

Universities in the European space are currently under increasing pressure due to increased competition from both new universities in Europe as well as from North American and Asian universities and also to the increased negative demographic trends.

According to Giannakouris (2010, p. 11-16), Europe's population is set to grow by $5 \%$ until 2030, with great differences between its countries and regions. For Romania, by 2030 , a population reduction of almost 1.3 million is expected, due to a negative natural increase of $-3.1 \%$ and a migration rate of $0.1 \%$.

Increasing the amount of intellectual capital requires two critical levers: managing its development and providing components and programs for information technology - the essential electronic elixir to gain more human, social and structural capital.

Labour-based learning offers the chance to fundamentally expand the intellectual capital of the university. Focusing on a university-based learning program as a process of recognizing, creating and applying knowledge through and for work rather than simply at work challenges the position of the university as a single validator and evaluator of high-level knowledge.

The need to demonstrate "purpose-matching" typically not only requires cognitive skills of traditional higher education (analysis, synthesis, evaluation), but also 
requires them to be applied in a complex situation to maximize the effectiveness of resources taking into account stakeholder expectations and time limits.

According to Dalkir (2005), coding is the final stage of the information acquisition process, after the initial stage of identifying the information source, and that of conceptualizing or understanding the information (see Figure 1).

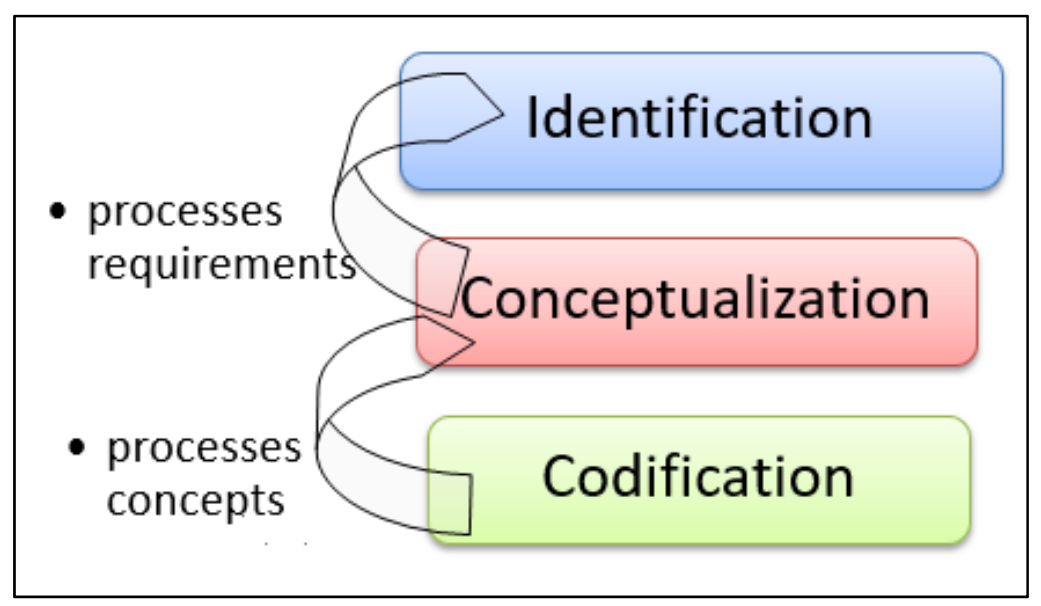

Figure 1: The stages of the information acquisition process after Dalkir

Two aspects of the coding stage are addressed by the authors: organization and outsourcing of knowledge. The organization of explicit knowledge includes three forms: cognitive maps, decision trees, and taxonomy.

The information we are interested in is taxonomically structured on the INS website (www1) on seven main categories: social, economic, finances, justice, environment, land administration and public utilities.

\section{LITERATURE REVIEW}

According to Tarlea and Freyberg-Inan (2018), in Romania, higher education is oriented towards providing low and medium quality education, while the economy is oriented towards the production of industrial goods and services that require small and medium skills. In short, Romania is rooted in a low balance of abilities.

The authors started from the premise that the political and economic implications of the deterioration of higher education in Romania from 1989 can be better understood by exploring the dynamics of demand and supply of higher education and high-level skills in the Romanian economy. They argue that an imbalance of skills has emerged in our country, where a medium-educated population produces goods and services with low added value. This would not only be a symptom 
INDEPENDENT JOURNAL OF MANAGEMENT \& PRODUCTION (IJM\&P)

http://Www.ijmp.jor.br

V. 10, n. 5, September-October 2019

ISSN: 2236-269X

DOI: 10.14807/ijmp.v10i5.924

of Romania's status as a dependent market economy but also helps explain the failure to overcome the quality deficiencies of the post-communist system in Romania.

The most likely way out of the current imbalance would be an evolution towards the liberal model, where universities provide general skills, and workplace preparation is done on the ground. Without an acceleration of the government's regulatory effort and expenditures to safeguard the quality of higher education, there is little hope in the country's ability to use better qualifications as a path to greater economic competitiveness.

Zamfir (2017) confirms the results of previous studies that highlight the persistence of educational gaps between rural and urban areas in developing countries. On the other hand, educational poverty has a positive overall trend. Unfortunately, younger generations account for a higher proportion of poorly educated people, especially in rural areas.

Moreover, the spread of new technologies (4G and $5 G$ networks for communication, mobile interfaces in the era of loT -Internet of Things) brings a new perspective for collaborative and distance learning that allows a balanced between work and social life for modern students.

They are keen of new technologies and IoT and come in university to experience knowledge through modern teaching methods such as VR (virtual reality) facilities integrated in E-learning platforms, in classrooms, in labs, in museums or libraries etc. Knowledge is everywhere now: on internet, in libraries, in schools, but is very difficult to access it, because the students must be initiated in the access of enormous data-warehouses and bigdata technologies.

Here comes knowledge management system that has to be offered by universities to students. These systems have to offer dynamic, interactivity, 3D visualization, Virtual reality experience as to improve education and knowledge acquisition having fun in the same time (NAZIM, 2016; SHUJAHAT, 2019; HERNÁNDEZ-LÓPEZ, 2016; PETROVA, 2015; ȚONIȘ, 2018a).

Knowledge management refers to design a model of innovation that facilitates the link between academia and the business environment is described in. The academies have to be a member of a business environment network (BEN), in which corporations and state institutions may invest in a performing open innovation platform 
INDEPENDENT JOURNAL OF MANAGEMENT \& PRODUCTION (IJM\&P)

http://Www.ijmp.jor.br

V. 10, n. 5, September-October 2019

ISSN: 2236-269X

DOI: 10.14807/ijmp.v10i5.924

and in licenses. In this ecosystem, students can come out with innovation in different fields. The innovation will be validated by an ecological agency as to be in accordance with circular economy principles.

This environment has to integrate a market agency to test the innovation on the market. The feasibility of the idea has to be tested by a consultant (financial) agency, that has to be part of the environment. Should all the tests finish with success, the inventors within the network and the academic researchers can come up with possible implementation solutions (XU, 2019; TONIS, 2018B; LINA, 2012).

Modern knowledge management system has to use Al technologies that are integrated in machine learning based on neural networks to image recognition based on hundreds of raw pictures of the given target to extract the most appropriated knowledge that the student is searching for. Thus, modern knowledge management system integrates deep learning and predictive analytics as machine learning methods. They also integrate translation, classification \& clustering, and information extractions as method of natural language processing (NLP). They also integrate speech, robotics and vision (image recognition and machine vision) as modern methods of AI (SAĞSAN, 2016; BRAICU, 2018).

Romania faces a phenomenon of human capital polarization. This means that, in the post-communist period, Romania recorded a simultaneous increase in the share of people with higher education and an increase in the share of people with lower secondary education. Moreover, the educational level according to the residence environment indicates that this polarization tends to increase the gap between an educated urban area and a poorly educated rural area.

\section{RESEARCH METHODOLOGY}

\subsection{The purpose and objectives of the research}

This paper aims to identify the factors influencing the qualitative and quantitative indicators of higher education in Romania, and how they varied between 2013 and 2016. The desire was to determine the medium-term tendencies in terms of youth employment in higher education, the share of students by specialization groups in the public and private environments and the average increase in residence environments, given the effective decrease in the number of pupils in high school education [www2]. 
The objective of the current research is to highlight the influence of knowledge management on the intellectual capital of the Romanian university environment. In this sense, a theoretical research was carried out in two stages:

1) the study of specialized literature in the field, accessing articles and books from international databases.

2) establishing the topic to be analyzed statistically, as a result of the previous stage: the evolution of the Romanian education and the determinants of this evolution:

a) choosing the variables to be entered in a statistical model: POP214A, SCL102A, SCL103L. The variable were choses in accordance with the anterior review section.

b) collection of data from the Social Statistics category from the INS database regarding the variables previously established for the period 2013-2016

c) choosing and implementing the statistical model

d) interpreting the results and formulating the conclusions.

\subsection{Methodology and aspects of the data analysed}

The research presented in the paper is an office research based on the statistical analysis of the social statistics category of the INS database, the subcategories:

- POP214A - Natural population growth by residence area, macro-regions, development regions and counties;

- SCL102A - Degree enrolment in education of the school age population, by sex;

- SCL103L - Undergraduates and students enrolled in higher education, by groups of specializations.

In the research, we have taken into account the factors that lead to the failure of knowledge management (FROST, 2014), among which we mention:

- Lack of performance indicators and metrics associated with the objectives pursued; 
INDEPENDENT JOURNAL OF MANAGEMENT \& PRODUCTION (IJM\&P)

http://www.ijmp.jor.br

V. 10, n. 5, September-October 2019

ISSN: 2236-269X

DOI: 10.14807/ijmp.v10i5.924

- Lack of relevance, quality and adequacy of information;

- Poor methodology and inappropriate use of statistical and IT tools.

The gthnk free system for knowledge management is the main way of retaining and transferring knowledge from the perspective of the General Knowledge Model (NEWMAN; CONRAD, 1999). The results of our research will be stored in this system in the form of text-based notes. In addition, it also provides long-term chronological storage of handwritten knowledge, notes on mobile devices and attached pictures, see Figure 2.

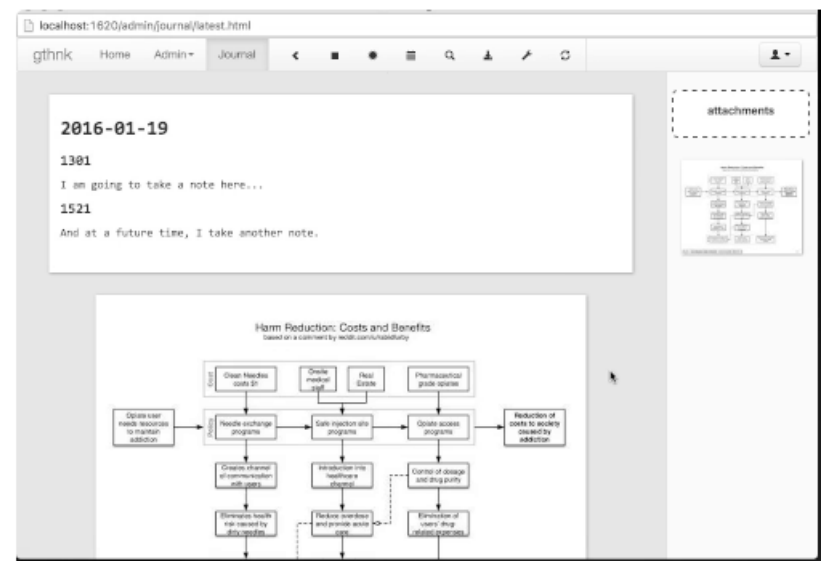

Figure 2: The gthnk system implemented in Python

Source: www6

According to Sandor (2013), the longitudinal research strategy, comprising at least two measuring intervals, allows us to study the evolution of social phenomena over time and even to identify a model to explain this evolution. In addition, in conducting case studies on mass phenomena, the aim is to compare the results obtained on different groups, e.g. population categories.

It can be seen in Figure 3 that natural growth followed a sharp decline between 2013 and 2015, especially in the rural area (from -3.5 to -5 ), followed by an overall stabilization (rural + urban) after 2015 (-4.4 in 2016). We consider that the trend of decreasing the number of rural populations through emigration was reversed by population migration from the city to the village amid the deindustrialization and aging of the urban population.

The percentage of population's education followed a downward trend amid negative natural growth and increase of school dropout (see Figure 4), Romania ranking third in the European Union in number of school dropouts. Malta ranks first (19.6\%), followed by Spain (19\%) and Romania (18.5\%), according to www3. Virtually, 
INDEPENDENT JOURNAL OF MANAGEMENT \& PRODUCTION (IJM\&P)

http://Www.ijmp.jor.br

V. 10, n. 5, September-October 2019

ISSN: 2236-269X

DOI: 10.14807/ijmp.v10i5.924

two out of ten students end up dropping out of school, most of them coming from the countryside and from poor families. In fact, Romania is one of the few countries where school dropout has increased in the last decade, from $17.9 \%$ in 2006 to $18.5 \%$ in 2016 , according to (MIHAI, 2018).

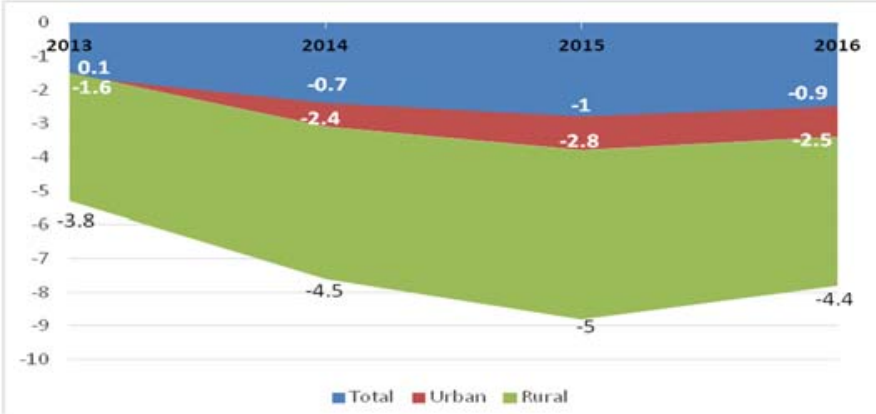

Figure 3: Natural population growth by residence area Source: own processing data from www4

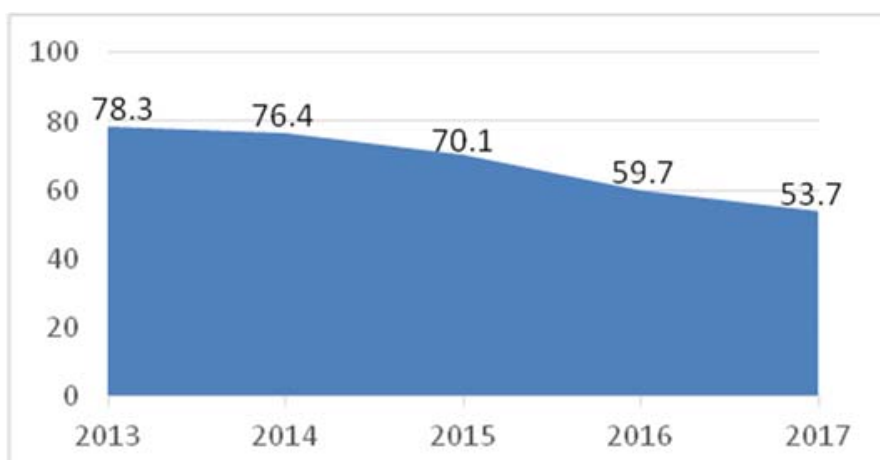

Figure 4: Degree of enrolment in school by age population Source: own processing data from www4

The situation of the students enrolled in higher education changed slightly between 2013 and 2016, the highest share having the full-time attendance education $-92 \%$, followed by the distance learning $-5 \%$ and the evening classes $-3 \%$, as it follows al the level of 2016, see Figure 5:

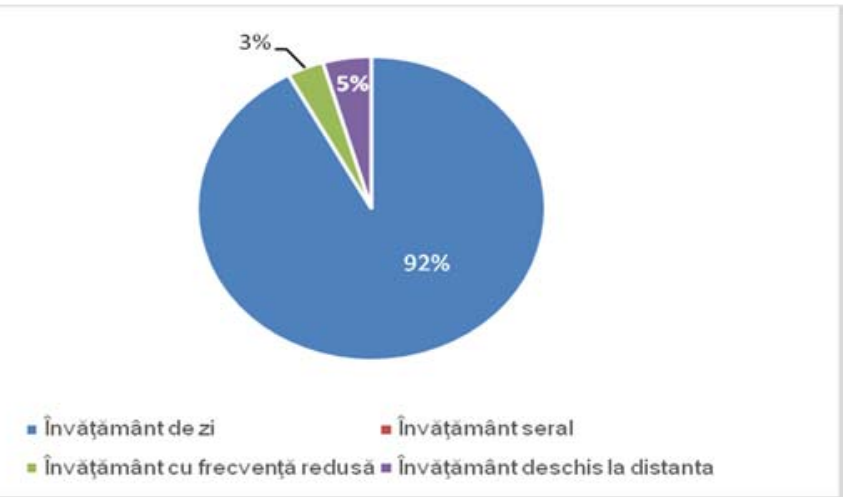

Figure 5: Share of students enrolled in higher education by types of education Source: processing after statistical information obtained from www4 
In private higher education, there has been a tendency to decrease the number of students enrolled in the 2013-2016 interval (from about 66,000 students to 56,402 students in full time attendance education), see figure 6 . Possible causes could be the supplementation of budget and tax places, as well as the elimination of the admission exam at the state universities.

The analysis of the evolution of the number of students in private and state higher education by specializations groups during the period 2013-2016 reveals the maintenance of a decreasing trend over the researched interval. Higher public economic education recorded the largest decrease in the interval taken into account, with $34 \%$ in 2016 compared to the reference year (2013), see Figure 7.

An upward trend has been recorded in the education sector, with an increase of $18.5 \%$ in 2016 compared to 2013 . An explanation could be the awareness of the importance of the teaching activity among young high school graduates, amid the gradual increase of the funds allocated from the public budget to this key sector for the economic development. The constant maintenance of the demand for jobs in the tertiary sector led to the preservation of the number of students enrolled in this specializations group at an average level of approx. 6,700 students per year on the surveyed interval.

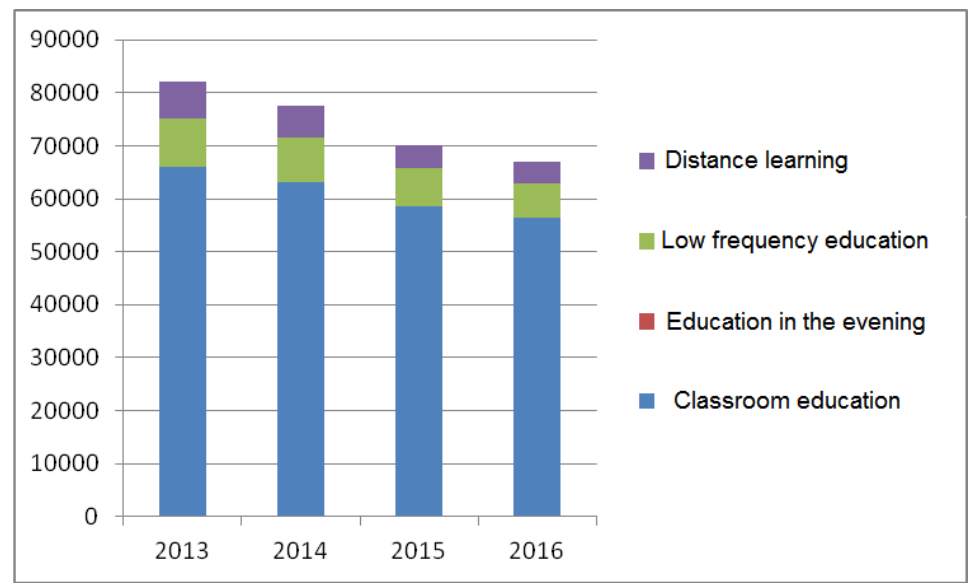

Figure 6: Students enrolled in private higher education Source: processing after statistical information obtained from www4 
DOI: 10.14807/ijmp.v10i5.924

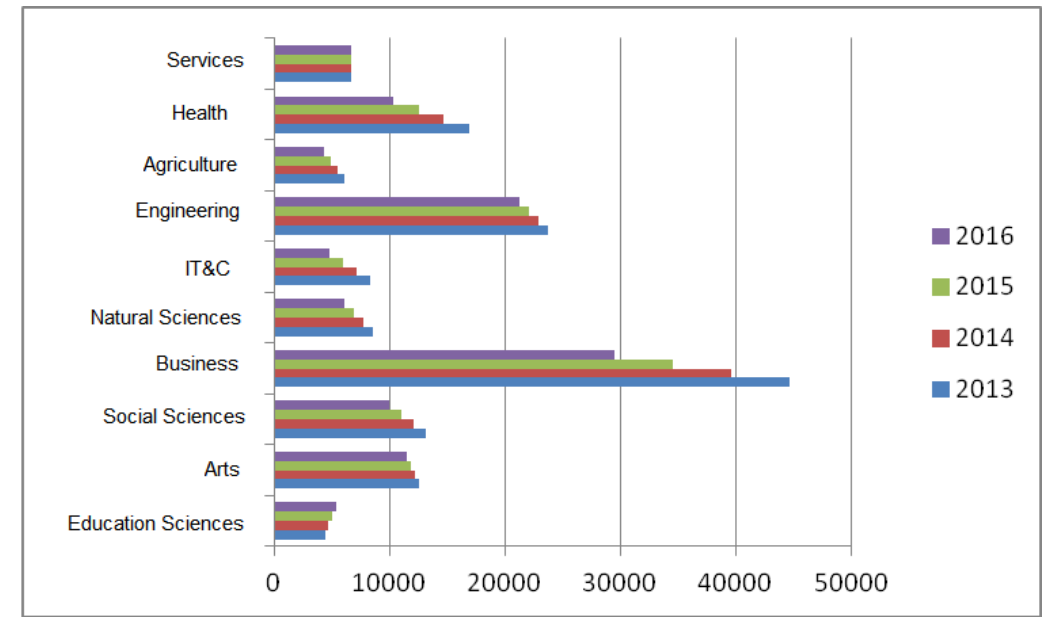

Figure 7: Analysis of the evolution of the number of students in public higher education

Source: processing after statistical information obtained from www4

As regards the students on specialization groups, we observe a high share of engineering and economic sciences in specializations total (19\% and $26 \%$ respectively in 2016), with a more pronounced tendency to reduce the number of students enrolled in economic sciences in 2014-2015 interval (from 39,625 students to 34,572 students). At the level of 2016, the share of students enrolled on specializations groups was as follows (see figure 8):

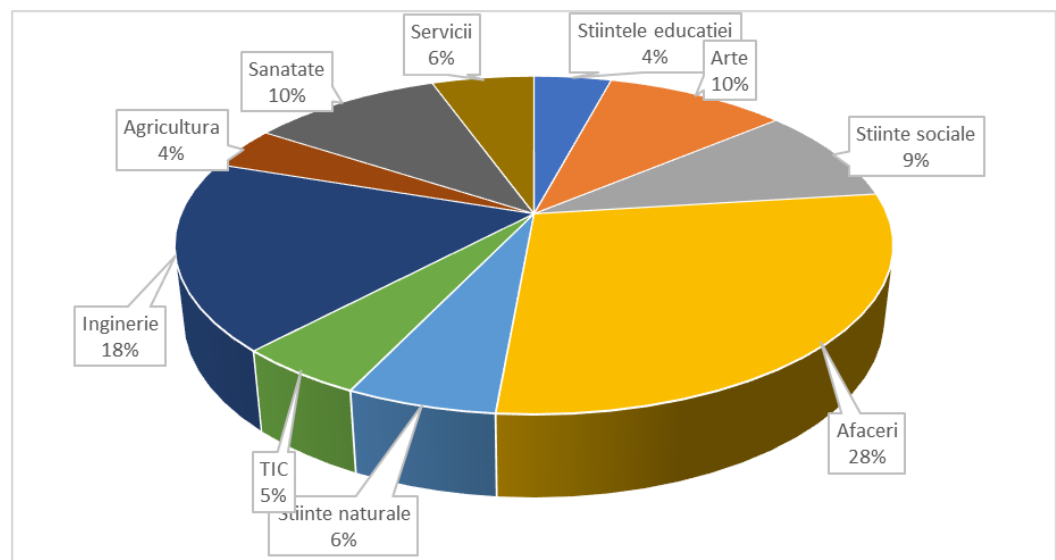

Figure 8: Share of students from public universities on specializations groups in 2016 Source: processing after statistical information obtained from www4

An interesting trend is found in students enrolled in the private sector, where the declining trend for the 2013-2016 period is reversed in the health specialization group (from 747 students in 2014 to 1,244 students in 2015). An explanation could be the increased need for doctors in West European hospitals.

The rest of the decreasing trend is manifested in all other specialization groups, including services and education. This trend is explained also by students' migration 
INDEPENDENT JOURNAL OF MANAGEMENT \& PRODUCTION (IJM\&P)

http://Www.ijmp.jor.br

V. 10, n. 5, September-October 2019

ISSN: 2236-269X

DOI: 10.14807/ijmp.v10i5.924

or the orientation of high school graduates from private higher education to the public, amid the gradual adaptation of the curriculum to the needs of the labor market and the supplementation of the budget and tax places in state universities, see figure 9.

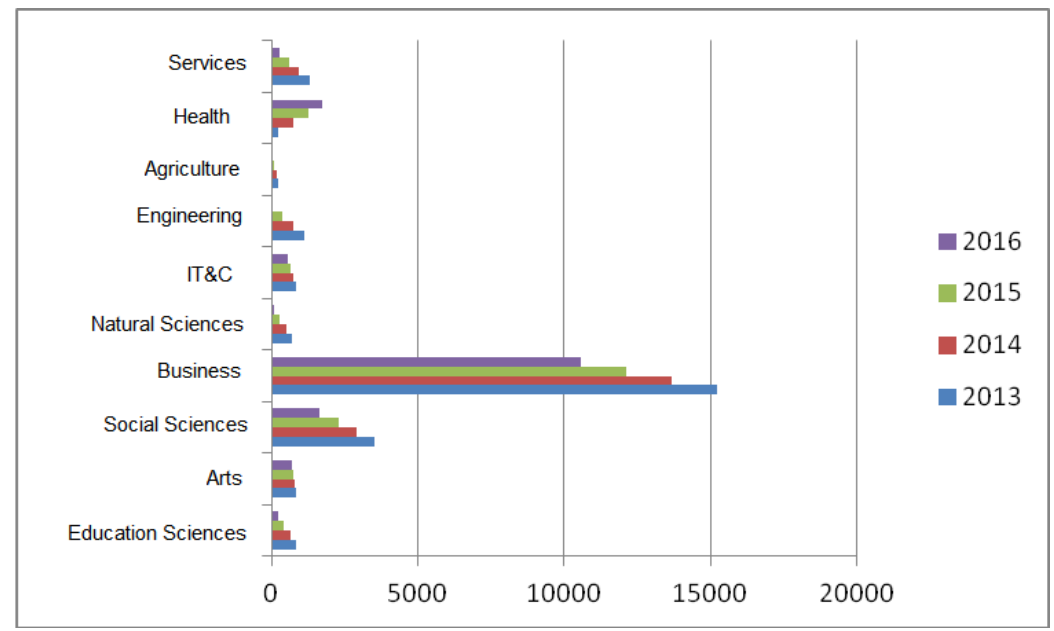

Figure 9: Analysis of the evolution of the number of students in private higher education

Source: processing after statistical information obtained from www4

The share of economic sciences in the total private university specializations as number of enrolled students is significantly higher than in the public system in 2016 (64\% vs. $28 \%)$, as shown in Figure 10:

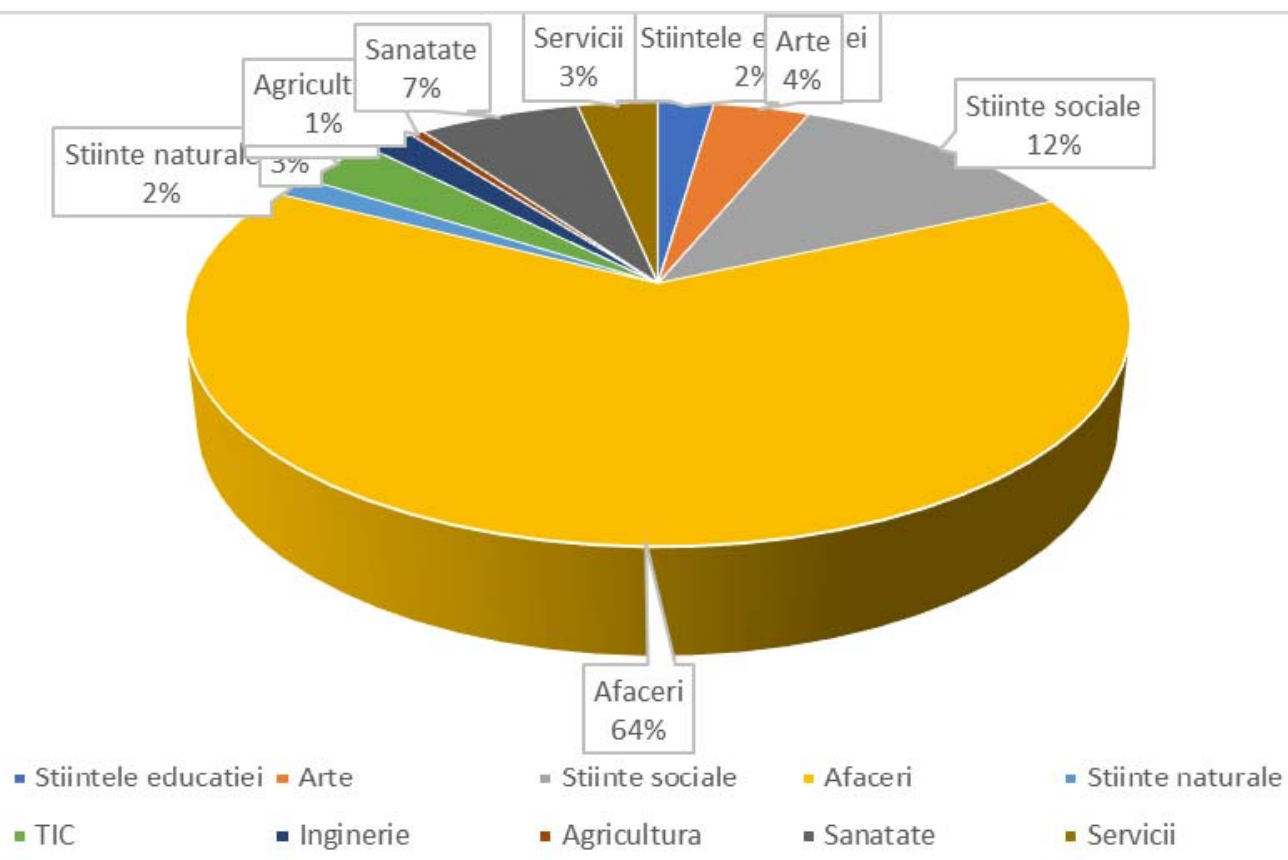

Figure 10: Share of students enrolled in the private sector on specializations groups in 2016

Source: processing after statistical information obtained from www4 
For a more in-depth analysis of the school population data series, we chose the pandas tool (www5) for Python. Pandas is an Open Source software library released under the BSD license for data manipulation and analysis. It provides data structures and algorithms for manipulating numerical data and time series. The name is derived from "Panel Data," an econometric term for data sets that include both time series and cross-sectional data.

We performed a simple data series analysis using the descrip() method applied to the df objectframe or data source. This step generates descriptive statistics summarizing the central trend, dispersion and form of distribution of a data set, excluding non-numeric values. The following script was implemented, resulting the table from figure 11 :

import pandas as pd

(...)

$d f=p d . r e a d \_c s v(' / h o m e / l i n u x l i t e / D e s k t o p / s u r s a 2 . c s v ')$

textview.get_buffer().insert_at_cursor(df.describe().to_string())

\begin{tabular}{|lrr|}
\multicolumn{1}{l}{$\boldsymbol{\nabla}$ Details } & An & Procent \\
& An & Py \\
count & 5.000000 & 5.000000 \\
mean & 2015.000000 & 67.640000 \\
std & 1.581139 & 10.651197 \\
min & 2013.000000 & 53.700000 \\
$25 \%$ & 2014.000000 & 59.700000 \\
$50 \%$ & 2015.000000 & 70.100000 \\
$75 \%$ & 2016.000000 & 76.400000 \\
max & 2017.000000 & 78.300000
\end{tabular}

Figure 11: Result of applying the describe() method to the data series

Source: report resulted by running the script above

For a complex analysis, we used pandas implementation of the smallest squares method (OLS) in estimating the regression equation parameters using the formula:

ols ('dependency variable $\sim$ independent variable', dataframe)

(2)

The source code is:

import pandas as pd

import statsmodels.api as sm

from statsmodels.formula.api import ols

(...)

$\mathrm{df}=$ pd.read_csv('/home/linuxlite/Desktop/sursa2.csv')

$\mathrm{m}=$ ols('An $\sim$ Procent',df).fit() 
print m.summary()

and following the execution of the above script it results the following synthetic report generated in the development console or in the terminal, see Figure 12:

\begin{tabular}{|c|c|c|c|c|}
\hline Q Console $\mathbb{X} \quad \mathrm{P}_{\mathrm{u}}$ PyUnit & & 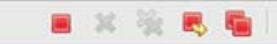 & 㖷雷 & $\Leftrightarrow$ 口 \\
\hline \multicolumn{5}{|c|}{ /root/git/pyGUI/myproj/radum/_init_.py } \\
\hline \multicolumn{5}{|c|}{ 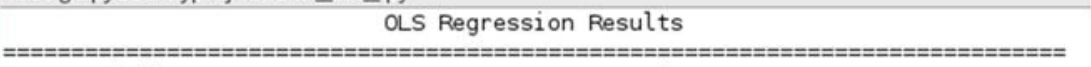 } \\
\hline \multicolumn{2}{|c|}{ Dep. Variable: An } & \multicolumn{2}{|c|}{ R-squared: } & 0.957 \\
\hline Model: & OLS & Adj. R-squared: & \multicolumn{2}{|r|}{0.943} \\
\hline Method: & Least Squares & \multicolumn{2}{|l|}{ F-statistic: } & 66.77 \\
\hline Date: & $\mathrm{Sb}, 17$ feb 2018 & Prob (F-statistic): & \multicolumn{2}{|r|}{0.00383} \\
\hline Time: & $09: 45: 16$ & Log-Likelihood: & & .0 .96091 \\
\hline No. Observations: & 5 & AIC: & & 5.922 \\
\hline Df Residuals: & 3 & BIC: & & 5.141 \\
\hline \multicolumn{5}{|l|}{ Df Model: } \\
\hline \multirow{2}{*}{\multicolumn{5}{|c|}{ 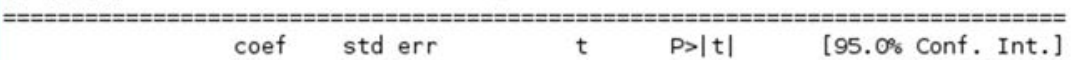 }} \\
\hline & & & & \\
\hline n. & & & & \\
\hline 2024.8227 & 1.214 & 0.000 & 2020.959 & 2028.686 \\
\hline Procent & 0.018 & 0.004 & -0.202 & -0.089 \\
\hline \multicolumn{5}{|c|}{ 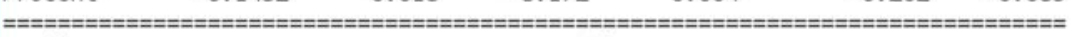 } \\
\hline Omnibus: & nan & Durbin-Watson: & & 1.880 \\
\hline Prob (Omnibus): & nan & Jarque-Bera (JB): & & 0.383 \\
\hline Skew: & -0.239 & $\operatorname{Prob}(\mathrm{JB}):$ & & 0.826 \\
\hline Kurtosis: & 1.732 & Cond. No. & & 490. \\
\hline
\end{tabular}

Figure 12: Estimation of regression coefficients

Own source: report resulted by running the script above

\subsection{Research results}

The determination coefficient R2 of this model is 0.957 . This indicates that $96 \%$ of the dependent variable are determined by the variation of the independent variable and only $4 \%$ of this influence cannot be explained using the model. Because R2 takes values closer to 1 , the regression model better adjusts the data in the sample. In this case, the value of 0.957 demonstrates the validity of the model (Figure 10), which proves that the influence of the independent variable is significant to explain the variance of the dependent variable.

Since the adjusted $R 2$ value is close to the $R 2$ value, this allows the extension of the proposed regression model for the entire population. In this case, the variance of the dependent variable decreases with the difference between the two coefficients $(0.957-0.943=0.034)$. It is noticeable that this difference is very low, below $1 \%$.

The simplest test to highlight the self-correction error is Durbin-Watson. In this case, the value $D_{-} W$ is 1.88 , roughly included in the $[2,4]$ interval. The conclusion is that there is no self-correction between errors.

The Akaike Criterion (AIC) is often used in selecting the model for different alternatives. Smaller AIC values are preferred. AIC is 5.92, having hence a low value. 
The $\mathrm{F}$ test for each variable validates the model and contributes to the predictive power of the regression model. The significance threshold of the variables should be less than 0.05 . In our case, it is 0.00383 , less than 0.05 after the $F$ statistical test.

The coefficient of the dependent variable has an estimated value of -0.1452 , with a probability of guaranteeing the (probable) results of 0.004 (lower than the sensitivity threshold of 0.05 ), so is validated the good estimation of this coefficient.

Based on the data series, the following graph is generated using the free pyGUI tool at https://github.com/radubm1/pyGUI/, over which we have overlapped the graph of the estimated trend equation, see Figure 13:

Figure 13: School enrolment rate of the school age population, real (blue) and estimated (red)

Source: processing after statistical information obtained from www1

Analyzing the data regarding the school enrolment of the school age population it results a more pronounced decrease of the percentage after 2015, a fact which should determine the institutional actors involved to take the necessary measures to reduce the dropout rate.

\section{CONCLUSIONS}

The research carried out confirms the stated supposition, namely the decrease of the number of high school graduates and thus the number of young people enrolled in accredited state and private university education.

The analysis of the data showed that the share of students enrolled in state education, from the total number of students, is $\sim 86 \%$, and from the point of view of the attractiveness of the specializations, the first place in held, both in public and private education, by the economic specializations with a share of $\sim 82 \%$ (public) and $\sim 62 \%$ (private) from the specializations total, even if the actual number of students in these specializations has decreased in the last years. 
At the same time, attractiveness for the specialization medicine has seen a growing trend over the period under review, although the actual number of young people enrolled in higher education -cycle I, license- has decreased (from 433234 in 2013 to 405638 in 2016).

Based on the trend equation calculated in the paper, it can be noticed that the number of young people enrolled in higher education in 2030 will be insignificant, if the negative demographic growth and the emigration will not be counteracted by immediate measures to increase birth rates, increase the attractiveness of the Romanian economy by creating new highly qualified jobs, attracting foreign students from less developed countries and, last but not least, running European Lifelong Learning programs and cooperation in the field of strategic partnerships in higher education.

Thus, achieving some stable strategies and policies, coherent in the field of university education, should be the key objective in the near future for all involved decision makers.

\section{REFERENCES}

BOHLOULI, M.; MITTAS, N.; KAKARONTZAS, G.; THEODOSIOU, T.; FATHI M. (2017) Competence assessment as an expert system for human resource management: A mathematical approach, Expert Systems with Applications, v. 70, p. 83-102.

BRAICU, C.; BUCEA-MANEA-TONIS, Ra.; BUCEA-MANEA-TONIS, Ro. (2018) Knowledge, Management based on Expert Systems, In 30th IBIMA CONFERENCE: 8-9 November 2017, Madrid, Spain, Vision 2020: Sustainable Economic development, Innovation Management, and Global Growth, p. 2258-2264.

BUCEA-MANEA-TONIS, Ro.; ANDRONIE, M.; IATAGAN, M. (2018) E-Learning in the Era of Virtual Reality, The 14th International Scientific Conference eLearning and Software for Education Bucharest, April 19-20.

BUCEA-MANEA-TONIS, Ro.; PISTOL, L.; BUCEA-MANEA-TONIS, Ra. (2018) Model of Innovation and Creativity in exchange between Universities and Business Field, The $14^{\text {th }}$ international scientific conference elearning and software for education Bucharest, April 19-20.

DALKIR, K. (2005) Knowledge Management in Theory and Practice. ButterworthHeinemann: Elsevier, pp. 94

FROST, A. (2014) A Synthesis of Knowledge Management Failure Factors, Available at: https://www.knowledge-management-tools.net, Accessed 15th November 2018, p.4. 
GIANNAKOURIS, K. (2010) Regional population projections EUROPOP2008: Most EU regions face older population profile in 2030. Statistics in Focus, v. 1. Luxembourg: Publications Office of the European Union.

HERNANDEZ-LOPEZ, L.; GARCIA-ALMEIDA, D. J.; BALLESTROS-RODRIGUES, J. L.; DE SAA-PEREZ, P. (2016) Students' perceptions of the lecturer's role in management education: Knowledge acquisition and competence development, The International Journal of Management Education, v. 14, n. 3, p. 411-421

LINA, Y. (2012) Constructing Networked Learning Community Based on the Education Knowledge Management Platform, Procedia Environmental Sciences, v. 12, Part B, p. 1324-1328

MIHAl, A. (2018) Ziarul Financiar, Viitor cenuşiu pentru România. Unu din cinci elevi părăseşte timpuriu şcoala, nivel aproape dublu faţă de media UE, http://www.zf.ro/eveniment/viitor-cenusiu-pentru-romania-unu-din-cinci-eleviparaseste-timpuriu-scoala-nivel-aproape-dublu-fata-de-media-ue-16247740, Accessed 07th November 2018

NAZIM, M.; MUKHERJEE, B. (2016) Knowledge Management in LibrariesConcepts, Tools and Approaches, p. 171-200, DOI: https://doi.org/10.1016/B9780-08-100564-4.00008-9

NEWMAN, B.; CONRAD, K. W. (1999) A Framework for Characterizing Knowledge Management Methods, Practices, and Technologies, George Washington University Course, p.3

PETROVA, G. I.; SMOKOTIN, V. M.; KORNIENKO, A. A.; ERSSHOVA, I. A.; KACHALOV, N. A. (2015) Knowledge Management as a Strategy for the Administration of Education in the Research University, Procedia - Social and Behavioral Sciences, v. 166, p. 451-455

SAGSAN, M.; MEDENI, I. T.; MEDENI, T. D. (2016) Knowledge Management Paradigms: Implementation through Individual Fuzzy-based Education, Procedia Computer Science, v. 102, p. 259-266.

SANDOR, S. D. (2013) Metode şi tehnici de cercetare în ştiinţele sociale Bucuresti: Ed.Tritonic, p. 56.

SHUJAHAT, M.; SOUSA, M. S.; HUSSAIN, S.; NAWAZ, F.; UMER, M. (2019) Translating the impact of knowledge management processes into knowledge-based innovation: The neglected and mediating role of knowledge-worker productivity, Journal of Business Research, v. 94, p. 442-450

TARLEA, S.; FREYBERG-INAN, A. (2018) The education skills trap in a dependent market economy. Romania's case in the 2000s. Communist and Post-Communist Studies, v. 51, n. 1, p. 49-61, Available at: https://www.sciencedirect.com/science/article/pii/S0967067X18300035?via\%3Dihub, Accessed 10th November 2018. DOI:10.1016/j.postcomstud.2018.01.003

VILTARD, L. A.; VILTARD, L. (2018) Corporate University: An implementation case analysis, in Argentina, Independent Journal of Management \& Production, v. 9, n. 4

XU, J.; HOU, Q.; NIU, C.; WANG, Y.; XIE, Y. (2019) Process optimization of the University-Industry-Research collaborative innovation from the perspective of knowledge management, Cognitive Systems Research, v. 52, p. 995-1003 
ZAMFIR, A-M. (2017) Urban-Rural Educational Inequalities and Human Capital Polarization in Romania. Revista Romaneasca pentru Educatie

Multidimensionala, v. 9, n. 3, p. 156-164.

${ }^{* * *}$ www1 INS - Romanian National Institute of Statistics

http://statistici.insse.ro/shop/index.jsp?page=tempo2\&lang=ro\&context=25,

Accessed 05th November 2018.

${ }^{* * *}$ www2 INS - Romanian National Institute of Statistics. http://www.insse.ro/cms/, Accessed 06th November 2018

***www3 AGERPRES, Romania este pe locul trei in UE la abandonul scolar, http://www.ziare.com/scoala/elevi/romania-este-pe-locul-trei-in-ue-la-abandonulscolar-1480381, Accessed 07th November 2018

${ }^{* * *}$ www4 INS - Romanian National Institute of Statistic, http://statistici.insse.ro/shop/index.jsp?page=tempo2\&lang=ro\&context=15, Accessed 05th November 2018.

****www5 https://pandas.pydata.org/ Accessed 7th November 2018.

${ }^{* * *}$ www6 http://www.gthnk.com/ Accessed 7th November 2018. 